\title{
Entre a Águia e o Dragão? 0 comércio exterior brasileiro diante de Estados Unidos e China
}

Between the Eagle and the Dragon? The Brazilian foreign trade before the United States and China

Rodrigo Regazonni de Oliveira ${ }^{1}$

\begin{abstract}
RESUMO
Tendo em conta a recente posição adotada por organizações industriais brasileiras em defesa de uma aproximação estratégica com os EUA e considerando a movimentação da China na América do Sul, este ensaio analisa as dificuldades reveladas pelo quadro comercial externo do Brasil e também busca avaliar em que medida o aprofundamento da relação bilateral com cada uma das potências contribui para o tratamento da questão.
\end{abstract}

Palavras-chave: Brasil; China; Estados Unidos.

\begin{abstract}
Taking into account recent position adopted by the Brazilian industrial organizations in support of a strategic proximity to the United States and also the China's movement in South America, this paper analyzes the Brazilian foreign trade difficulties and considers to what extent the increase of bilateral relations with each great power contribute to deal with the issue.
\end{abstract}

Key-words: Brazil; China; United States.

\section{Introdução}

O presente ensaio pretende veicular uma análise das dificuldades reveladas pelo quadro comercial externo brasileiro e também avaliar em que medida o aprofundamento da relação com norte-americanos ou chineses pode contribuir para o tratamento da questão. 0 trabalho, embora tome a atual conjuntura circunscrita à área do comércio exterior como referência, contempla também o exame de alguns pontos do curso histórico recente, de modo a buscar identificar - em linhas gerais - a orientação adotada pela política externa brasileira (PEB) no tratamento da matéria e levantar suas principais implicações para a consecução do déficit da balança comercial apresentado atualmente.

\footnotetext{
${ }^{1}$ Mestre em História, UnB. Distrito Federal, Brasil. 


\section{0 quadro atual do comércio exterior brasileiro}

Os números divulgados pelo Ministério do Desenvolvimento, Indústria e Comércio Exterior (MDIC) sobre a balança comercial brasileira, em 2014, refletem um quadro inquietante. 0 déficit observado no ano, de cerca de US\$ 4 bilhões, foi o pior para um ano fechado desde 1998, quando foi identificado um saldo negativo de US\$6,6 bilhões (MINISTÉRIO DA INDÚSTRIA, COMÉRCIO E DESENVOLVIMENTO, 2015a). 0 fraco desempenho, longe de derivar apenas dos efeitos de uma conjuntura internacional não muito favorável, pode ser visto também como um resultado da manutenção de determinadas posições em nível doméstico, em que destacamos a prioridade conferida à atuação em bloco por meio do MERCOSUL. No que tange à exploração de oportunidades voltadas a ampliar o acesso de produtos nacionais nos mercados mundiais, o saldo obtido ao longo dos últimos mandatos presidenciais se revelou extremamente diminuto em seu escopo e alcance geográfico: somente dois acordos de liberalização comercial vigentes com Índia e Israel e dois em processo de ratificação com Palestina e Egito (MINISTÉRIO DAS RELAÇÕES EXTERIORES, 2015a). Ademais, as negociações em favor de um acordo comercial com a União Europeia (UE) também não têm gerado expectativas muito otimistas, em face das dificuldades de se alcançar consensos sobre vários pontos controversos. Em um momento onde várias frentes de promoção ao comércio estão sendo arquitetadas, como a Parceria Transpacífico, a das Américas, a da Oceania e a Parceria Transatlântica, o isolamento do Brasil - com todos os custos de oportunidade que a situação acarreta - torna-se cada vez mais evidente.

Os riscos decorrentes da pequena disposição do país em buscar o seu lugar em um mundo cada vez mais caracterizado pela disputa por acesso privilegiado a mercados aumenta à medida que suas vendas ao exterior passam a contribuir cada vez menos para o Produto Interno Bruto (PIB). Em 2014, as exportações representaram 11,5\% da soma de bens e serviços produzidos pelo país, muito abaixo da média global, de 29,8\% (FOLHA DE S. PAULO, 2015a). De acordo com um levantamento realizado com base em informações fornecidas pelo Banco Mundial, o Brasil apresentou o sexto menor percentual entre 150 países analisados, à frente somente de Afeganistão, Burundi, Sudão, República Centro-Africana e Kiribati (idem). Com suas exportações correspondendo apenas a 1,18\% do total mundial em 2014 (WORLD TRADE ORGANIZATION, 2015), o quinto maior país do mundo em extensão territorial, bem 
como em população absoluta, revela ser ainda uma economia consideravelmente fechada, consequência direta do predomínio de políticas de caráter desenvolvimentista aplicadas ao longo de décadas, marcadas pelo intervencionismo político, protecionismo e pouca integração às redes produtivas globais.

Afora os dados a respeito do peso em relevância das exportações brasileiras, cabe aqui abordar o perfil destas. Conforme podemos constatar no quadro abaixo, há uma visível preponderância do setor primário frente ao segmento composto por produtos manufaturados e semifaturados.

Tabela 1 - Desempenho das Exportações (US\$ milhões - FOB / 2014)

\begin{tabular}{|c|c|c|c|}
\hline & Valor & $\begin{array}{c}\text { Variação em \% entre } \\
2013 / 2014\end{array}$ & Participação \% \\
\hline Exportação total & 225.101 & $-7,0$ & 100,0 \\
\hline Básicos & 109.556 & $-3,1$ & 48,7 \\
\hline Manufaturados & 80.211 & $-13,7$ & 35,6 \\
\hline Semifaturados & 29.065 & $-4,8$ & 12,9 \\
\hline
\end{tabular}

Fonte: MINISTÉRIO DAS RELAÇÕES EXTERIORES. Dados do MDIC/SECEX/Aliceweb, jan. 2015.

Com quase metade da pauta de exportações constituída por matérias primas, pode-se inferir o quanto o desempenho das vendas externas nacionais - nas condições apresentadas - encontra-se suscetível de sofrer impactos com as oscilações dos preços das commodities no mercado internacional. Assim, a queda dos preços do barril de petróleo, do minério de ferro e de outros insumos observada em 2014 colocou à mostra os problemas oriundos de uma nação que mantém ainda um forte caráter agroexportador, introvertido e com uma balança comercial tendente a acumular déficits em face da ampliação do número de importações. Por sua vez, o desempenho das vendas de manufaturados - que poderia contribuir positivamente para reduzir a gravidade do quadro - sofreu uma queda significativa: 13,7\%. Entre os fatores que colaboraram para isto, podemos citar a redução das vendas para os países do MERCOSUL, em especial para a Argentina (MINISTÉRIO DAS RELAÇÕES EXTERIORES, 2015b), tradicional sorvedouro de manufaturados brasileiros como automóveis e máquinas. Cabe acrescentar que a situação das trocas com o país vizinho tem sido prejudicada pelo fato de seu governo aplicar com frequência ações protecionistas para restringir a entrada de produtos 
brasileiros, atitude que configura uma agressão aos objetivos preconizados pelo MERCOSUL. Assim, com a queda dos fluxos de comércio entre os dois países, em larga medida devido a medidas restritivas aplicadas pela ex-presidente Cristina Kirchner, o Brasil tende a perder mercados para as suas vendas externas de manufaturas, quadro minorado somente com o aumento das exportações deste segmento com destino a outro importante parceiro comercial: os EUA.

\section{0 peso da economia norte-americana}

Com um Produto Interno Bruto (PIB) nominal de US\$ 17,42 trilhões e crescimento de 2,4\% em 2014, os EUA mantiveram o posto de maior economia do mundo (WORD BANK, 2015). O setor de serviços é o principal ramo de atividade e respondeu por $79,4 \%$ do total da riqueza produzida, seguido do industrial com 19,5\% e do agrícola com 1,1\%. 0 país responde sozinho por $10 \%$ do fluxo de todo o comércio internacional, de acordo com a OMC. Seu comércio exterior apresentou, em 2013, crescimento de $46,9 \%$ em relação a 2009 , de US\$ 2,66 trilhões para US\$ 3,91 trilhões. No ranking da ONU/UNCTAD de 2013, assumiu a posição de segundo maior mercado mundial, sendo o segundo exportador e o primeiro importador (MINISTÉRIO DAS RELAÇÕES EXTERIORES, 2015c).

Os EUA ocupam uma posição de destaque junto ao comércio exterior brasileiro, sendo o $2^{\circ}$ maior parceiro do país. Entre 2010 e 2014, o intercâmbio comercial brasileiro com os norte-americanos cresceu 33,8\%, de US\$ 46,35 bilhões para US\$ 62,03 bilhões. No período em referência, as exportações cresceram $40 \%$ e as importações, 29,4\% (idem). Contudo, é preciso destacar um ponto muito importante: o saldo da balança comercial tem sido favorável aos EUA em todo o período, conforme aponta o quadro a seguir. 
Tabela 2 - Evolução do intercâmbio comercial entre Brasil e EUA (US\$ bilhões - FOB / 2014)

\begin{tabular}{|c|c|c|c|c|c|c|c|}
\hline \multirow{2}{*}{ Ano } & \multicolumn{2}{|c|}{ Exportações } & \multicolumn{2}{|c|}{ Importações } & \multicolumn{2}{|c|}{ Intercâmbio comercial } & \multirow{2}{*}{ Saldo } \\
\hline & Valor & Var. \% & Valor & Var. \% & Valor & Var. \% & \\
\hline 2010 & 19,31 & 23,8 & 27,04 & 35 & 46,35 & 30,1 & $-7,74$ \\
\hline 2011 & 25,8 & 33,7 & 33,97 & 25,6 & 59,77 & 29 & $-8,17$ \\
\hline 2012 & 26,7 & 3,5 & 32,36 & $-4,7$ & 59,06 & $-1,2$ & $-5,66$ \\
\hline 2013 & 24,65 & $-7,7$ & 36,02 & 11,3 & 60,67 & 2,7 & $-11,37$ \\
\hline 2014 & 27,03 & 9,6 & 35 & $-2,8$ & 62,03 & 2,2 & $-7,97$ \\
\hline
\end{tabular}

Fonte: MINISTÉRIO DAS RELAÇÕES EXTERIORES. Dados do MDIC/SECEX/Aliceweb, jan. 2015.

Ademais, as vendas brasileiras com destino aos EUA são compostas, em sua maior parte, por manufaturados. Tais produtos corresponderam a 50,6\% do conjunto em 2014 (com destaque para a venda de máquinas mecânicas, aviões e combustíveis). Os básicos, por sua vez, representam 23,6\% das vendas (petróleo em bruto e café) e os semimanufaturados (ferro e aço e pastas de madeira), 19,8\%. Por outro lado, as importações norte-americanas no comércio com o nosso país são dominadas por manufaturados, que respondem por 92,9\% do total das compras em 2014 (destaque para máquinas mecânicas e elétricas, óleo diesel, produtos químicos orgânicos e plásticos). Os básicos vem em seguida, compondo 5,8\%, com destaque para hulha betuminosa; semifaturados, 1,4\% (idem).

Pelo exposto, se por um lado acumulamos sucessivos déficits na relação com os EUA, por outro há certamente uma valiosa oportunidade a explorar: o comércio de manufaturados. Na condição de maior destino das exportações brasileiras afeitas ao segmento, os EUA foram responsáveis por embarques de US\$15,1 apenas para produtos do setor em 2014 (idem). Com a recuperação de sua economia e tendo em conta a queda do real no Brasil, estima-se uma elevação da compra destes produtos. Há também notícias promissoras para o setor primário de nossa economia oriundas do Norte: em julho do ano passado, o departamento de agricultura dos EUA assinou um acordo com representantes do Ministério da Agricultura para reabrir as importações da carne in natura do Brasil, que estiveram proibidas nos últimos 15 anos. A medida, embora esteja condicionada a inspeções sanitárias por parte dos norte-americanos em frigoríficos e rebanhos nacionais, enseja novas oportunidades de negócios não só no mercado 
americano, mas em muitos outros. De acordo com o presidente da Associação Brasileira das Indústrias Exportadoras de Carne (ABIEC), Antônio Jorge Camardelli,

A entrada pro mercado americano vai facilitar o nosso acesso a países que ainda utilizam artifícios comerciais travestidos de barreiras técnicas e por termos esse passaporte agora, a gente pode ter acesso a um dos quatro maiores importadores mundiais e que também praticam melhores preços, citando Coreia do Sul, Taiwan, Japão e Indonésia. (GLOBO RURAL, 2015).

Assim, para além das variações do mercado internacional, resulta evidente a importância crítica a ser conferida ao esforço por maior acesso aos principais mercados. No entanto, é sabido que a condução da matéria, sob a forma de acordos de maior amplitude, exige muitas vezes uma fina sintonia entre os atores políticos envolvidos, em virtude de sua imbricação com outros pontos sensíveis, tais como compras governamentais, regulamentações, propriedade intelectual e prestação de determinados serviços. Por oportuno, cabe questionar: o que o histórico recente da relação bilateral com os EUA nos informa a esse respeito?

\section{Brasil e EUA: desencontros e possibilidades de acerto}

Historicamente, as relações bilaterais entre Brasil e EUA exibem uma série de altos e baixos, de ensaios de aproximação a distanciamentos pragmáticos nas dimensões política e comercial. Com a ascensão do Partido dos Trabalhadores (PT) à Presidência da República, a partir de 2003, nítidas mudanças puderam ser percebidas junto à dinâmica do padrão relacional. Embora os contatos iniciais entre os presidentes Luiz Inácio Lula da Silva e George W. Bush tenham gerado expectativas positivas quanto à formulação de uma agenda bilateral promissora, a situação não logrou avanços. No âmbito continental, as divergências entre as duas nações acirravam-se gradativamente no interior do processo negociador da Área de Livre Comércio das Américas (ALCA), paralisado desde o ano de 2005. Posteriormente, a atenção conferida pelo Brasil à exploração de mercados periféricos (relações Sul-Sul), às parcerias em nível sub-regional (MERCOSUL e UNASUL) e à formação de grupos de interesse com outras nações emergentes pelo globo (IBAS e BRIC) deixaram claro que a orientação adotada pelo país em sua busca por maior espaço comercial e político no cenário internacional não pressupunha aprofundar as suas relações com os grandes centros desenvolvidos, particularmente com os EUA. 
Por sua vez, durante o primeiro mandato de Dilma Rousseff (2011-2014), não foram observadas modificações de fundo no relacionamento bilateral, a despeito da assinatura de acordos setoriais e até de uma declaração de apoio, dada pela então secretária de Estado norte-americana, Hillary Clinton, em favor de um acordo de livre comércio entre seu país e o Brasil (MERCOPRESS, 2012). Para além da retórica, nenhuma sinalização foi dada pelo governo brasileiro para empreender um estudo sobre a proposta, que despertou até mesmo o interesse da Confederação Nacional da Indústria (CNI), na pessoa de seu então presidente, Robson Braga, na ocasião em que discursava para uma plateia de 200 empresários norte-americanos na sede do Federal Reserve Bank of Kansas City, na cidade de Denver, Colorado (CONFEDERAÇÃo NACIONAL DA INDÚSTRIA, 2013). Todavia, a tomar a condução da PEB nos últimos anos, a pouca movimentação em favor da exploração das oportunidades com os EUA não surpreende, haja vista a preferência dada ao incremento de parcerias e acordos envolvendo países emergentes, em especial os chineses.

\section{O lugar da China no comércio exterior brasileiro}

Com PIB nominal estimado em US\$10,35 trilhões e crescimento de 7,3\% em 2014, a China ocupa a segunda posição entre as maiores economias do mundo, atrás dos EUA (WORLD BANK, 2015). 0 setor terciário (serviços) é o principal ramo de atividade e responde por $46,1 \%$ do total da riqueza produzida, seguido do industrial com 43,9\%, e da agricultura com 10,0\%. 0 comércio exterior do país apresentou, no ano de 2013, crescimento de 88,4\% em relação a 2009 , de US\$ 2,21 trilhões para US\$ 4,16 trilhões, sendo crescimento de 83,8\% nas exportações e de 93,9\% nas importações. No ranking da UN/UNCTAD de 2013, o país figurou como o segundo mercado mundial, após os EUA, sendo o primeiro exportador e o segundo importador (MINISTÉRIO DAS RELAÇÕES EXTERIORES, 2015d).

Entrementes, a China, com participação de 17,2\% no comércio exterior deste país em 2014, afigura-se como o principal parceiro comercial do Brasil. Entre 2010 e 2014, o intercâmbio comercial brasileiro com o país aumentou 38,3\%, de US\$56,38 bilhões para US\$ 77,96 bilhões. Durante o período, as exportações e importações cresceram, respectivamente, 31,9 e 45,9\%. 0 saldo da balança comercial, favorável ao 
Brasil ao longo do período, registrou superávit de US\$ 3,28 bilhões em 2014, conforme podemos constatar no quadro abaixo (idem).

Tabela 3 - Evolução do intercâmbio comercial entre Brasil e China (US\$ bilhões - FOB / 2014)

\begin{tabular}{|c|c|c|c|c|c|c|c|}
\hline \multirow{2}{*}{ Ano } & \multicolumn{2}{|c|}{ Exportações } & \multicolumn{2}{|c|}{ Importações } & \multicolumn{2}{c|}{ Intercâmbio comercial } & \multirow{2}{*}{ Saldo } \\
\cline { 2 - 7 } & Valor & Var. \% & Valor & Var. \% & Valor & Var. \% & \\
\hline 2010 & 30,79 & 46,6 & 25,6 & 60,9 & 56,38 & 52,7 & 5,19 \\
\hline 2011 & 44,31 & 43,9 & 32,79 & 28,1 & 77,11 & 36,8 & 11,52 \\
\hline 2012 & 41,23 & -7 & 34,25 & 4,5 & 75,48 & $-2,1$ & 6,98 \\
\hline 2013 & 46,03 & 11,6 & 37,3 & 8,9 & 83,33 & 10,4 & 8,72 \\
\hline 2014 & 40,62 & $-11,8$ & 37,34 & 0,1 & 77,96 & $-6,4$ & 3,28 \\
\hline
\end{tabular}

Fonte: MINISTÉRIO DAS RELAÇÕES EXTERIORES. Dados do MDIC/SECEX/Aliceweb, jan. 2015.

Diferentemente do perfil das exportações para os EUA, 84,4\% das vendas externas brasileiras para a China, em 2014, foram compostas por matérias primas, com destaque para soja, minério de ferro e óleo bruto de petróleo. Por sua vez, os manufaturados corresponderam a 4\% (gorduras e óleos); semimanufaturados, com um percentual maior, representaram 11,5\% (açúcar e fumo). Todavia, no que se refere às importações, a pauta de compras brasileiras oriundas da China é quase inteiramente dominada por manufaturados: 98,0\% do conjunto, com destaque para máquinas, produtos químicos, plásticos, automóveis, vestuário e instrumentos de precisão. Os básicos responderam por 1,8\%; já os semimanufaturados, 0,2\% (idem).

A despeito dos sucessivos superávits alcançados no comércio com a China, o quadro de trocas demonstra ser pouco diversificado. Apresenta, além de uma ampla concentração de itens primários na pauta exportadora nacional, uma tendência para o aumento das compras de manufaturados do país asiático. Sobre este cenário, e tendo em conta a crescente presença chinesa na América do Sul, quais oportunidades e inconvenientes um eventual aprofundamento das relações sino-brasileiras poderia comportar? 


\section{O papel do Dragão junto aos interesses comerciais estratégicos do Brasil: oportunidades e riscos}

Desde o estabelecimento das relações comerciais entre os dois países, ocorrido durante a década de setenta, Brasil e China exibem um promissor comércio bilateral, cuja evolução se observa a cada ano. De 1974 a 2014, o intercâmbio saltou de US\$ 19,4 milhões para quase US\$ 78 bilhões em 2014, tendo os chineses, em 2009, superado os norte-americanos como os maiores parceiros comerciais do Brasil (MINISTÉRIO DO DESENVOLVIMENTO, INDÚSTRIA E COMÉRCIO EXTERIOR, 2015b). No campo diplomático, observa-se uma sintonia de interesses sino-brasileiros demonstrados com a criação de iniciativas como o Fórum de Cooperação Ásia do Leste-América Latina (FOCALAL), no ano de 2001; do G-20 voltado à OMC, no ano de 2003 e do grupo BRIC, em 2009 (que dois anos depois se converteu em BRICS, com a adesão da África do Sul). Atualmente, a cooperação também se constitui em uma das principais fontes de investimento diretos no Brasil, com destaques para os setores de energia, mineração, siderurgia e agronegócio.

O entendimento acerca do potencial da relação para a consecução de benefícios mútuos levou as duas nações a assinarem mais de 30 acordos em maio do ano passado, com previsão de cerca de US\$ 50 bilhões em investimentos no Brasil (FOLHA DE S. PAULO, 2015b). Ademais, não poderíamos deixar de salientar a entrada em operação do Novo Banco de Desenvolvimento (NBD), a partir de uma iniciativa do BRICS. A nova instituição tem como finalidade se colocar como uma alternativa ao Banco Mundial (BM) e ao Fundo Monetário Internacional (FMI), de acordo com seu diretor, o indiano Kundapur Vaman Kamath (AGÊNCIA EFE, 2015). A instituição busca financiar uma maior cooperação entre os cinco países-membros, cujo somatório de suas populações corresponde a $41,4 \%$ do total mundial e mais de $25 \%$ do PIB global. A previsão da formação de reservas de contingências, com um fundo de US\$ 100 bilhões - US\$ 41 bilhões deles garantidos pela China - para reagir às possíveis "contingências" inesperadas da economia internacional, representa uma clara sinalização, por parte dos chineses, de liderar frentes com o propósito de diminuir a influência exercida pelos EUA sobre as finanças globais (idem).

Afora as oportunidades suscitadas com a perspectiva de adensamento do relacionamento bilateral, o envolvimento mais estreito com a China também pode 
sinalizar, no plano de horizonte, um custo a ser pago pelo Brasil em termos de perda de projeção regional. Neste contexto, cabe mencionar a crescente presença chinesa na Argentina, consolidada com a assinatura recente de um amplo acordo de cooperação econômica bilateral que prevê, entre outras medidas, a adjudicação a empresas chinesas de obras de infraestrutura construídas no país beneficiadas com financiamentos oriundos da China. A cooperação - além de compreender empreendimentos públicos e de infraestrutura - avança também sobre áreas importantes como energia, manufatura, mineração, tecnologia e agricultura. Pesou bastante para a tessitura de um acordo com tais dimensões a previsão de um swap (troca de moedas) envolvendo US\$ 11 bilhões em favor da Argentina - fato que teria evitado a radicalização da crise econômica pela qual passa (MERCOPRESS, 2015). No Equador, bancos estatais da China estão por trás da construção de estradas, pontes e hospitais, tendo destinado quase US\$ 11 bilhões ao país na forma de investimentos, financiamentos e empréstimos. Todavia, a potência asiática tem cobrado, a título de contrapartida, a obediência às regras financeiras impostas por ela (THE NEW YORK TIMES, 2015).

Por causa destes termos, várias nações em desenvolvimento estão a pagar juros elevados e dispondo de seus recursos naturais durante anos por força de compromissos adotados com os chineses. No caso equatoriano, estes já controlam quase $90 \%$ das exportações de petróleo do país, como forma de garantia de pagamento pelos empréstimos concedidos. Na condição de expoente industrial do mundo, a China tem buscado soluções para garantir o fundamental suporte energético. Nos últimos anos, as empresas estatais chinesas adquiriram grandes participações em operações de petróleo em Camarões, Canadá, Cazaquistão, Quirguistão, Iraque, Nigéria, São Tomé e Príncipe, Sudão, Uganda, EUA e Venezuela (idem), sem contar a sua participação prevista na exploração do campo de Libra nas profundezas do pré-sal brasileiro (VALOR ECONÔMICO, 2013). Assim, tendo por base a "voracidade" demonstrada pelo dragão na perseguição aos seus interesses pelo mundo, é possível estimar que uma parceria de grande alcance com os asiáticos poderia exigir um preço muito elevado, haja vista a forma como buscam atrelar o que podem oferecer com aquilo que pretendem controlar em conformidade com seus propósitos de grande potência. 


\section{Considerações Finais}

O histórico recente da movimentação diplomática brasileira não deixa dúvidas quanto à orientação assumida pela PEB desde 2003, no sentido de priorizar as relações com países emergentes - via formação de grupos de interesse - e operar a sua locomoção na exploração de vantagens no plano do comércio internacional a partir do MERCOSUL. No que tange propriamente a este último aspecto, conforme já observamos, a orientação em referência não resultou na obtenção de vantagens, ganhos expressivos ou mesmo perspectivas de progresso para a maior capilaridade das exportações brasileiras junto aos mercados externos mais pujantes. No âmbito do boom das commodities caracterizado pela expansão do consumo chinês, o Brasil alcançou superávits sucessivos e uma ampliação significativa de suas relações comerciais com a nação asiática.

Entretanto, e tendo em conta a configuração atual do quadro comercial bilateral e seu plano de horizonte, a questão acerca da possibilidade de se elevar da parceria a um patamar de maior adensamento suscita pontos cuja complexidade requer precaução, haja vista a probabilidade da iniciativa vier a comportar dois graves riscos: o da especialização produtiva em commodities - refletido pela pauta de exportação brasileira - e a consequente perda de influência regional com a crescente presença dos chineses não só no país como também no restante da América do Sul. A considerar a hipótese de agravamento do quadro econômico que experimentamos atualmente, a geração de superávits na balança comercial e a atração de investimentos internacionais de grande vulto tornar-se-ão essenciais no esforço pela recuperação, a constituir em um cenário de alta vulnerabilidade à sedução crédito abundante oferecido pelo Dragão a custos questionáveis.

Por outro lado, uma reorientação em busca de uma parceria privilegiada com os EUA também poderia viabilizar a consecução de progressos em várias frentes, haja vista a expertise dos norte-americanos em setores sensíveis, como o científico-tecnológico. De um modo geral, o mercado destes oferece mais estabilidade e transparência, visto que se trata de uma nação democrática e com amplas liberdades civis e econômicas. Entre outras possibilidades, a partir dos EUA como centro de gravidade, pode-se admitir como factível e oportuna a formação de um acordo em prol da maior abertura dos mercados nacionais do continente, com base em uma agenda estruturada e voltada à intensificação 
dos fluxos de comércio e com maior previsão de investimentos, sem maiores riscos ou custos de impacto crítico para o desenvolvimento e inserção internacional de nosso país.

\section{Referências}

AGÊNCIA EFE. Empieza a funcionar el Nuevo Banco de Desarrollo de países emergentes BRICS. Disponível em: <http://www.efe.com/efe/america/economia/empieza-a-funcionar-el-nuevo-banco-dedesarrollo-paises-emergentes-brics/20000011-2669477>. Acesso em: 02 nov. 2015.

ALMEIDA, Paulo Roberto de. Relações Brasil-EUA no início do século 21: desencontros. Boletim Mundorama, 2015. Disponível em: <http://www.mundorama.net/2015/06/28/relacoes-brasileua-no-inicio-do-seculo-21-desencontros-por-paulo-roberto-de-almeida/>. Acesso em: 16 jul. 2015.

. O Brasil e a agenda econômica internacional: Como se apresenta o cenário econômico internacional da atualidade? Boletim Mundorama, 2015. Disponível em: <http://www.mundorama.net/2015/04/15/o-brasil-e-a-agenda-economica-internacional-comose-apresenta-o-cenario-economico-internacional-da-atualidade-por-paulo-roberto-de-almeida/> . Acesso em: 16 jul. 2015.

BRASIL. CONSTITUIÇÃO da República Federativa do Brasil de 1988. Senado Federal, Brasília, 1999.

CERVO, Amado e BUENO, Clodoaldo. História da política exterior do Brasil. Brasília: Editora da UnB/IBRI, 2002.

CONFEDERAÇÃO NACIONAL DA INDÚSTRIA. Robson Braga de Andrade defende acordo de livre comércio entre Brasil e Estados Unidos. Disponível em: <http://www.portaldaindustria.com.br/cni/imprensa/2013/11/1,28798/robson-braga-deandrade-defende-acordo-de-livre-comercio-entre-brasil-e-estados-unidos.html>. Acesso em: 06 ago. 2015.

DIAS, Reinaldo. RODRIGUES, Waldemar. Comércio exterior. Teoria e gestão. São Paulo: Editora Atlas, 2004.

FOLHA DE S. PAULO. Só 5 países exportam menos que o Brasil em proporção do PIB. Disponível em: <http://www1.folha.uol.com.br/mercado/2015/07/1661171-so-5-paises-exportam-menos-que-obrasil-em-proporcao-do-pib.shtml>. Acesso em: 04 de ago. 2015a. 
Brasil e China confirmam acordos de mais de US\$ 53 bi e ajuda à Petrobras. Disponível em: $<$ http://www1.folha.uol.com.br/mercado/2015/05/1630920-brasil-e-china-assinam-acordos-demais-de-us-53-bilhoes.shtml>. Acesso em: 02 nov. 2015b.

GLOBO RURAL. EUA liberam importação de carne bovina in natura do Brasil. Brasil, julho de 2015. Disponível em: <http://g1.globo.com/economia/agronegocios/noticia/2015/07/eua-liberamimportacao-de-carne-bovina-natura-do-brasil.html >. Acesso em: 06 ago. 2015.

LIMA, Maria Regina Soares de. SANTOS, Fabiano. Brazilian Congress and Foreign Trade Policy. Prepared for delivery at the 1998 meeting of the Latin American Studies Association. The Palmer House Hilton Hotel, Chicago, Illinois, September 24-26, 1998.

MAQUIAVEL, Nicolau. O Príncipe. Rio de Janeiro: Editora Elsevier, 2003.

MENEZES, Albene M. et al. 20 anos da SECEX. 200 anos de comércio exterior. A história da SECEX e o comércio exterior brasileiro após a abertura dos portos. Ministério do Desenvolvimento, Indústria e Comércio Exterior, 2010.

MERCOPRESS. SOUTH ATLANTIC NEWS AGENCY. US/Brazil discuss energy cooperation and closer economic ties even free trade agreement. Disponível em: http://en.mercopress.com/2012/04/17/us-brazil-discuss-energy-cooperation-and-closereconomic-ties-even-free-trade-agreement. Acesso em: 03 jan. 2015.

Argentine Congress approves 'strategic integral alliance' agreements with China. Disponível em: $<$ http://en.mercopress.com/2015/02/27/argentine-congress-approves-strategic-integral-allianceagreements-with-china >. Acesso em: 07 ago. 2015.

MINISTÉRIO DA INDÚSTRIA, COMÉRCIO E DESENVOLVIMENTO. Evolução do Comércio Exterior Brasileiro: $1950 \quad$ a 2013.2 Disponível em: $<$ http://www.mdic.gov.br//sitio/interna/interna.php?area=5\&menu=608>. Acesso em: 04 ago. 2015a.

- Outras estatísticas de comércio exterior. Disponível em: $<\mathrm{http}$ //www.mdic.gov.br/sitio/interna/interna.php?area=5\&menu=608>. Acesso em: 02 nov. 2015b.

MINISTÉRIO DAS RELAÇõES EXTERIORES. Acordos extrarregionais do MERCOSUL. Disponível em: $<$ http://www.itamaraty.gov.br/index.php?option=com_content\&view=article\&id=695:acordosextrarregionais-do-mercosul\&catid=140\&lang=pt-BR\&Itemid=593>. Acesso em: 04 ago. 2015a. 


$$
\text { Brasil - Argentina. Intercâmbio Comercial. Disponível em: }
$$

<http://www.brasilglobalnet.gov.br/ARQUIVOS/IndicadoresEconomicos/INDargentina.pdf>. Acesso em: 04 ago. 2015b.

Brasil - Estados Unidos. Intercâmbio Comercial. Disponível em: <http://www.brasilglobalnet.gov.br/ARQUIVOS/IndicadoresEconomicos/INDargentina.pdf>. Acesso em: 04 ago. 2015c.

Brasil - China. Intercâmbio Comercial. Disponível em: <http://www.brasilglobalnet.gov.br/ARQUIVOS/IndicadoresEconomicos/INDchina.pdf>. Acesso em: 04 ago. $2015 \mathrm{~d}$.

OLIVEIRA, Rodrigo Regazonni. Quem tem medo do lobo mau? Algumas considerações sobre a posição da Confederação Nacional da Indústria (CNI) em favor de um acordo de livre comércio entre Brasil e EUA. Boletim 2013.2 Disponível em: <http://www.mundorama.net/2013/11/19/quem-tem-medo-do-lobo-mau-algumasconsideracoes-sobre-a-posicao-da-confederacao-nacional-da-industria-cni-em-favor-de-umacordo-de-livre-comercio-entre-brasil-e-eua-por-rodrigo-regazonni-de-olivei/>. Acesso em: 06 de ago. 2015.

PAUTAÇ0, Diego. O lugar da China no comércio exterior brasileiro. Boletim Meridiano 47, 2010. Disponível em: <file://C:/Users/Rodrigo/Downloads/480-1470-1-PB.pdf>. Acesso em: 16 jul. 2015.

PRESIDÊNCIA DA REPÚBLICA. Principal parceiro comercial desde 2009, China amplia investimentos no Brasil. Portal Planalto, $2015 . \quad$ Disponível em: <http://www2.planalto.gov.br/noticias/2015/05/principal-parceiro-comercial-desde-2009-chinaamplia-investimentos-no-brasil>. Acesso em: 16 jul. 2015.

PUTNAM, Robert D. Diplomacy and domestic politics: the logic of two level games. In: International Organization, 42(1), Autumn, p. 427-460, 1988.

SARAIVA, José Flávio S. (org). História das Relações Internacionais Contemporâneas: da sociedade internacional européia do século XIX à globalização. São Paulo: Editora Saraiva, 2007.

THE NEW YORK TIMES. China's Global Ambitions, With Loans and Strings Attached. Disponível em: http://www.nytimes.com/2015/07/26/business/international/chinas-globalambitions-with-loans-and-strings-attached.html?_r=0>. Acesso em: 21 jul. 2015. 
WORLD BANK. Countries. Disponível em: <http://www.worldbank.org/en/country>. Acessado em: 02 nov. 2015.

VALOR ECONÔMICO. Consórcio de chinesas, Shell, Total e Petrobras arremata Libra. Disponível em: <http://www.valor.com.br/brasil/3311254/consorcio-dechinesas-shell-total-e-petrobras-arremata-libra>. Acesso em: 04 nov. 2015.

WORLD TRADE ORGANIZATION. Trade Profiles. Disponível em: <http://stat.wto.org/CountryProfiles/BR_E.htm>. Acesso em: 04 ago. 2015. 